\title{
Four-trophic level food webs reveal the cascading impacts of an invasive plant targeted for biocontrol
}

\author{
Francisco A. López-NúÑez (iD) ${ }^{1}$ Ruben H. Heleno, ${ }^{1}$ Sérgio Ribeiro, ${ }^{1}$ \\ Hélia Marchante, ${ }^{1,2}$ and Elizabete Marchante ${ }^{1,3}$ \\ ${ }^{1}$ Centre for Functional Ecology, Department of Life Sciences, University of Coimbra, \\ Calçada Martim de Freitas, 3000-456, Coimbra, Portugal \\ ${ }^{2}$ Department of Environment, Coimbra Polytechnic Institute, Higher School of Agriculture, Bencanta, 3045-601, Coimbra, Portugal
}

\begin{abstract}
Biological invasions are a major threat to biodiversity and as such understanding their impacts is a research priority. Ecological networks provide a valuable tool to explore such impacts at the community level, and can be particularly insightful for planning and monitoring biocontrol programmes, including the potential for their seldom evaluated indirect non-target effects. Acacia longifolia is among the worst invasive species in Portugal, and has been recently targeted for biocontrol by a highly specific gall-wasp. Here we use an ambitious replicated network approach to: (1) identify the mechanisms by which direct and indirect impacts of A. longifolia can cascade from plants to higher trophic levels, including gallers, their parasitoids and inquilines; (2) reveal the structure of the interaction networks between plants, gallers, parasitoids and inquilines before the biocontrol; and (3) explore the potential for indirect interactions among gallers, including those established with the biocontrol agent, via apparent competition. Over a 15-month period, we collected 31,737 galls from native plants and identified all emerging insects, quantifying the interactions between 219 plant-, 49 galler-, 65 parasitoid- and 87 inquiline-species - one of the largest ecological networks to date. No galls were found on any of the 16 alien plant species. Invasion by $A$. longifolia caused an alarming simplification of plant communities, with cascading effects to higher trophic levels, namely: a decline of overall gall biomass, and on the richness, abundance and biomass of galler insects, their parasitoids, and inquilines. Correspondingly, we detected a significant decline in the richness of interactions between plants and galls. The invasion tended to increase overall interaction evenness by promoting the local extinction of the native plants that sustained more gall species. However, highly idiosyncratic responses hindered the detection of further consistent changes in network topology. Predictions of indirect effects of the biocontrol on native gallers via apparent competition ranged from negligible to highly significant. Such scenarios are incredibly hard to predict, but even if there are risks of indirect effects it is critical to weigh them carefully against the consequences of inaction and invasive species spread.
\end{abstract}

Key words: alien plants; biocontrol; biological control agent; gallers; inquilines; multi-trophic networks; non-target effects; parasitoids; Portugal; species-interaction networks.

\section{INTRODUCTION}

Biological invasions are a characteristic of the Anthropocene and one of the main causes of the global biodiversity crisis (Chornesky and Randall 2003, Binimelis et al. 2007, Dirzo et al. 2014). By integrating into recipient communities, alien species often promote changes to the composition and interactions between resident species with changes varying greatly in their direction and magnitude (Pyšek et al. 2012). For example, invasive alien plants, i.e., those that spread rapidly in their new environment, can replace native vegetation, thereby changing the habitat structure, and disrupting pollination and seed dispersal systems by competing with native plants for mutualists (Montero-Castaño and Vilà 2012, Heleno

Manuscript received 18 July 2016; revised 21 October 2016; accepted 29 November 2016. Corresponding Editor: Sergio A. Navarrete.

${ }^{3}$ Corresponding Author. E-mail: emarchante@uc.pt et al. 2013, Marchante et al. 2015). It has been shown that some of these impacts can cascade through food webs, negatively affecting higher trophic levels (Heleno et al. 2009). However, such indirect impacts are seldom evaluated as they often require the implementation of demanding community-level monitoring protocols (White et al. 2006, McCary et al. 2016). One under-looked mechanism that might promote such indirect effects is apparent competition, i.e., when a species negatively affects other species of the same trophic level by increasing the abundance of their shared natural enemies (Morris et al. 2005, van Veen et al. 2006, Carvalheiro et al. 2008).

In recent decades, interaction networks have been increasingly used in ecology as a valuable tool to explore community level processes by allowing a holistic perspective from where species and the interactions that maintain functional communities can be simultaneously evaluated (Memmott 2009, Heleno et al. 2014). Ecological networks are thus a tool that allow us to disentangle the 
complexity of biological communities (Bascompte 2009). Paradoxically, most networks built to date are oversimplistic as they tend to focus only on two sets of interacting species (i.e., bipartite networks), most frequently plants and their insect pollinators, or plants and their vertebrate dispersers (Olesen et al. 2010, Fontaine et al. 2011). If ecological networks are to reach their full potential to inform ecologists and conservation managers, they need to incorporate indirect interactions across multiple trophic levels (Henneman and Memmott 2001, Carvalheiro et al. 2008).

One specific area where a network approach can be most useful is in planning and evaluating biocontrol programmes by allowing quantification of direct and indirect interactions during the planning, implementation and monitoring phases (Willis and Memmott 2005, Carvalheiro et al. 2008). By providing us with successive snapshots of community structure, networks can be particularly useful to contrast the post-release community structure with a pre-release reference structure of that same community. Such a holistic approach is vital to detect unforeseen changes in the presence, abundance, and interaction patterns across all species in the community and not only on a small group of target species where effects are expected. However, we are not aware of any study where information on the community structure has been gathered prior to the release of a biocontrol agent, hindering the prospects of a detailed evaluation of biocontrol success and of potential non-target effects (Simberloff and Von Holle 1999, White et al. 2006). Moreover, while most biocontrol programs assess non-target effects via direct interactions, they still largely ignore non-target effects mediated by indirect interactions.

Acacia longifolia (Andrews) Willd. was introduced in Portugal in the early 20th century to curb sand erosion (Neto 1993), and rapidly became one of the most widespread invasive plants in the country. Throughout the coast, $A$. longifolia severely changed natural dune systems by altering plant communities (Marchante et al. 2003, 2015), soil biological processes (Marchante et al. 2008a, $b$ ), nutrient and water cycling (Werner et al. 2010) and fire regimes (Marchante et al. 2003). Nevertheless, the impact of A. longifolia invasion on insect communities and the potential for these impacts to cascade through the food webs to higher trophic levels remains unexplored. In particular, it is important to understand if the impacts of this aggressive invader are restricted to the native vegetation or if they also affect the diversity, abundance and biomass of phytophagous insects and their predators (Pfisterer et al. 2002, Heleno et al. 2009, Redfern 2011).

A biological control programme for $A$. longifolia using the highly specific gall-wasp Trichilogaster acaciaelongifoliae (Froggatt, 1892) (Hymenoptera: Pteromalidae) has been planned since 2003 and was first implemented in November 2015 in Portugal (Marchante et al. 2011a, Shaw et al. 2016). This biocontrol agent is successfully used to control A. longifolia in South Africa (Dennill 1987), where it reduces seed production and vegetative fitness by inducing the formation of a gall tissue in floral and vegetative buds (Dennill 1985). However, plant galls frequently support complex and species-rich communities including the gall-forming insects (hereafter gallers), their parasitoids and a complex array of gall-inquilines (hereafter inquilines), i.e., arthropods that use these structures for feeding and protection (Shorthouse et al. 2005, Redfern 2011). The successful establishment of the biocontrol agent is expected to largely increase the availability of its galls in the environment, which may indirectly affect the native gall communities. In Australia T. acaciaelongifoliae galls have parasitoids (Neser 1984) and after the biocontrol's introduction in South Africa several native parasitoids affected it (Hill and Hulley 1995, Manongi and Hoffmann 1995, Veldtman et al. 2011). Despite the high specificity and efficacy of $T$. acaciaelongifoliae as a biocontrol agent of $A$. longifolia (Hoffmann et al. 2002), these new interactions could lead to potential indirect effects, such as apparent competition between native gallers and the biocontrol agent via shared parasitoids, which in the extreme could lead to local extinction of native galler species (Carvalheiro et al. 2008). In this context, it is vital to implement a detailed monitoring program which allows the evaluation of direct and indirect effects of this biocontrol agent, and ecological networks represent the most informative approach to attain this goal (Thomas et al. 2004, Carvalheiro et al. 2008, Barratt et al. 2010).

Using a comprehensive data set including four trophic levels and replicated interaction networks, the objectives of this study are threefold: (1) identify the mechanisms by which the direct and indirect impacts of $A$. longifolia invasion cascade from plants to higher trophic levels, including gallers, their parasitoids and inquilines; (2) reveal the structure of the interaction networks between plants, gallers, parasitoids and inquilines, prior to the release of the biocontrol agent, so that its success can be measured in the future; and (3) explore the potential for indirect interactions among galler species, including those established with the biocontrol agent, via apparent competition.

Since most species of gallers are confined to one specific host plant (Shorthouse et al. 2005), we predict that the replacement of diverse native plant communities by A. longifolia monospecific stands will decrease the diversity of host plants available to gallers, thus reducing their abundance, diversity and biomass. These changes will then cascade to higher trophic levels, equally reducing the abundance, diversity and biomass of parasitoids and inquilines. Furthermore, we expect that some native parasitoids, particularly the most generalists, might be able to exploit the galls formed by the biocontrol agent, potentially increasing in abundance and in turn affecting native galls.

\section{Materials And Methods}

We applied a space-for-time substitution approach (Pickett 1989, Osenberg et al. 2006) to evaluate the 
effects of Acacia longifolia invasion on the community of plants, gallers, their parasitoids and inquilines, prerelease of the biocontrol agent. Impacts were measured on classical measures of diversity (species richness, abundance and biomass) and on the structure of the whole community by implementing an ambitious, replicated, ecological network approach.

\section{Experimental design and sampling}

Ten sampling sites were selected along the distribution range of $A$. longifolia in Portugal (Appendix S1: Fig. S1). Four of these sites were visited monthly between August 2013 and October 2014 (i.e., prior to the release of the biocontrol agent), using a balanced design. On each visit, three random linear transects of $20 \times 2 \mathrm{~m}$ were selected on each site, totalizing 12 transects per month. Percentage cover of $A$. longifolia was estimated using a quadrat-grid system and level of invasion of each transect classified accordingly: Low invasion $0-29 \%$ cover; Intermediate invasion 30-69\% cover; and High invasion 70-100\% cover. Transects were carefully inspected for galls. All plants were identified, and galls were characterized, counted and collected to rear any developing insect under laboratory conditions. Only when the quantity of morphologically similar galls on the same host plant made collection impossible, these were counted and subsampled. All transects were marked with a GPS and were at least $50 \mathrm{~m}$ apart from any other transect. Data originated from these regular-sampling sites were complemented by seasonal visits to six extra sites near the limits of the A. longifolia distribution area (Appendix S1: Fig. $\mathrm{S} 1$ and Table S1). The extra-sampling sites were sampled in the same way and allowed us to build a more complete network, increasing the likelihood of sampling potentially rare interactions, which may be important both for conservation purposes and to explore potential interactions with the biocontrol agent.

All galls collected were individually stored and maintained in the lab for at least $1 \mathrm{yr}$. During this period, all galls were inspected weekly and any emerging insects were collected and identified to the lowest taxonomical level possible, usually species, by professional taxonomists. Based on specialized literature (see Appendix S2), all insects emerging from the galls were assigned to one of the following guilds: galler, parasitoid or inquiline.

Different gallers induce the formation of highly characteristic galls and therefore there is a very high correspondence between gall type and galler species (Russo 2006, Redfern 2011, Redfern and Shirley 2011). Since the formation of galls in plant organs is indicative of the contact with a gall-forming insect, we used the frequency of gall types as a proxy of galler abundance and diversity. This is a fair assumption given that all galls require the contact with a galler insect, which might not emerge in the lab either because it has emerged in the field previously to the collection of the gall or due to sub-optimal rearing conditions in the lab (Redfern 2011). The overall biomass of gall tissue (as the plant biomass allocated to the production of gall tissue) was estimated by weighing 10 galls of each species and extrapolating for the total weight of galls found per transect. Arthropod biomass was estimated by extrapolating arthropod individual weights obtained with the length-biomass conversion formulas proposed by Gruner (2003).

In addition to the impacts on common biodiversity descriptors of plants, gallers, parasitoids and inquilines, we also evaluated the impacts on the diversity of the interactions established between these four trophic levels, namely the interactions between plants and gallers, gallers and parasitoids, and galls and inquilines.

\section{Community structure}

In order to detect impacts of $A$. longifolia invasion on the overall community structure, we implemented a quantitative network approach, using the four regularlysampled sites. This approach can identify consistent changes to key descriptors of network topology, namely: connectance, nestedness, interaction evenness, and network specialization (Bascompte 2010, Heleno et al. 2014). Network connectance reflects the realized proportion of all possible links (Warren 1994, Heleno et al. 2012a); interaction evenness expresses the uniformity of interaction frequencies (Blüthgen et al. 2006); nestedness (WNODF) reflects the departure of a perfectly nested, i.e., hierarchical distribution of interactions (Almeida-Neto et al. 2008); and network specialization $\left(\mathrm{H}_{2}{ }^{\prime}\right)$ reflects the selective assortment of interactions in the network (Blüthgen et al. 2006). Networks were visualized with specific code written in Mathematica (Wolfram Research), and the main network descriptors were calculated with package bipartite 2.05 (Dormann et al. 2008) for R v3.2.2 (R Core Team 2015).

Finally, interactions from all sites were assembled into a single tripartite ecological network quantifying the interactions between plants, gallers, parasitoids and inquilines that characterize the Portuguese gall communities prior to the release of the biocontrol agent.

\section{Potential for apparent competition among galler species}

The magnitude of the indirect effect of galler species on other gallers, i.e., apparent competition, is proportional to the fraction of shared natural enemies (i.e., parasitoids) between each species pair (Tack et al. 2011). We projected bipartite galler-parasitoid interactions into a unipartite galler-galler interaction network where galler species were considered to interact whenever they shared at least one parasitoid species. The potential for apparent competition (PAC) between all gallers from the overall network (all sites) was then calculated with function PAC in package bipartite (Dormann et al. 2008), which estimates the proportion of shared parasitoids between galler species (ranging between zero, when no parasitoids are shared, and one, when all parasitoids are shared). 
In order to further explore the potential of the biocontrol agent to affect the galler community, we visualized the current PAC network and highlighted the galler species that are likely to indirectly interact with the biocontrol agent under two disparate scenarios: (1) a conservative scenario where the biocontrol is predicted to interact only with currently known parasitoids from Australia and South Africa; and (2) a liberal scenario where the biocontrol agent is predicted to interact with all species from all the families for which at least one parasitoid of Trichilogaster acaciaelongifoliae is currently known.

\section{Statistical analysis}

The effect of $A$. longifolia invasion on the richness and abundance of plants, gallers, parasitoids, and inquilines and on the biomass of galls, parasitoids, and inquilines was evaluated with generalized linear mixed models, including the percentage of $A$. longifolia invasion as a continuous fixed factor and the four regularly-sampled sites as a random factor. For each variable, the most appropriate error distribution was selected, namely: Poisson distribution for plant and gall richness, zeroinflated Poisson for inquiline richness, zero-inflated negative binomial for parasitoid richness and Gaussian distribution for the remaining variables. The same analysis was performed to evaluate the effect of invasion on the number of unique interactions (i.e., interaction richness) per transect, assuming Poisson distributed errors. Models were implemented with packages lme4 (Bates et al. 2015) and glmmADMB (Fournier et al. 2012) in R v3.2.2 (R Core Team 2015).

The effect of $A$. longifolia invasion on network structure descriptors was evaluated including invasion level (low, intermediate and high) and network size (considered as number of species of lower level $\times$ number of species of higher level) as fixed factors and site as random factor on a general linear mixed model.

\section{RESUlTS}

Overall, 219 plant species were identified along all transects, of which $93 \%$ were native and only 16 species were introduced, including Acacia longifolia (Fig. 1). On 33 of these plants, a total of 31,737 individual galls were formed due to the action of 49 galler species (Fig. 1). The vast majority $(74 \%)$ of the galls were formed on plant leaves, $10 \%$ on inflorescences, $8 \%$ on stems, $7 \%$ on buds, and $0.02 \%$ on fruits.

Most plants with galls were infected by only one or two galler species (level of specialization $=2.09$ galler species $/$

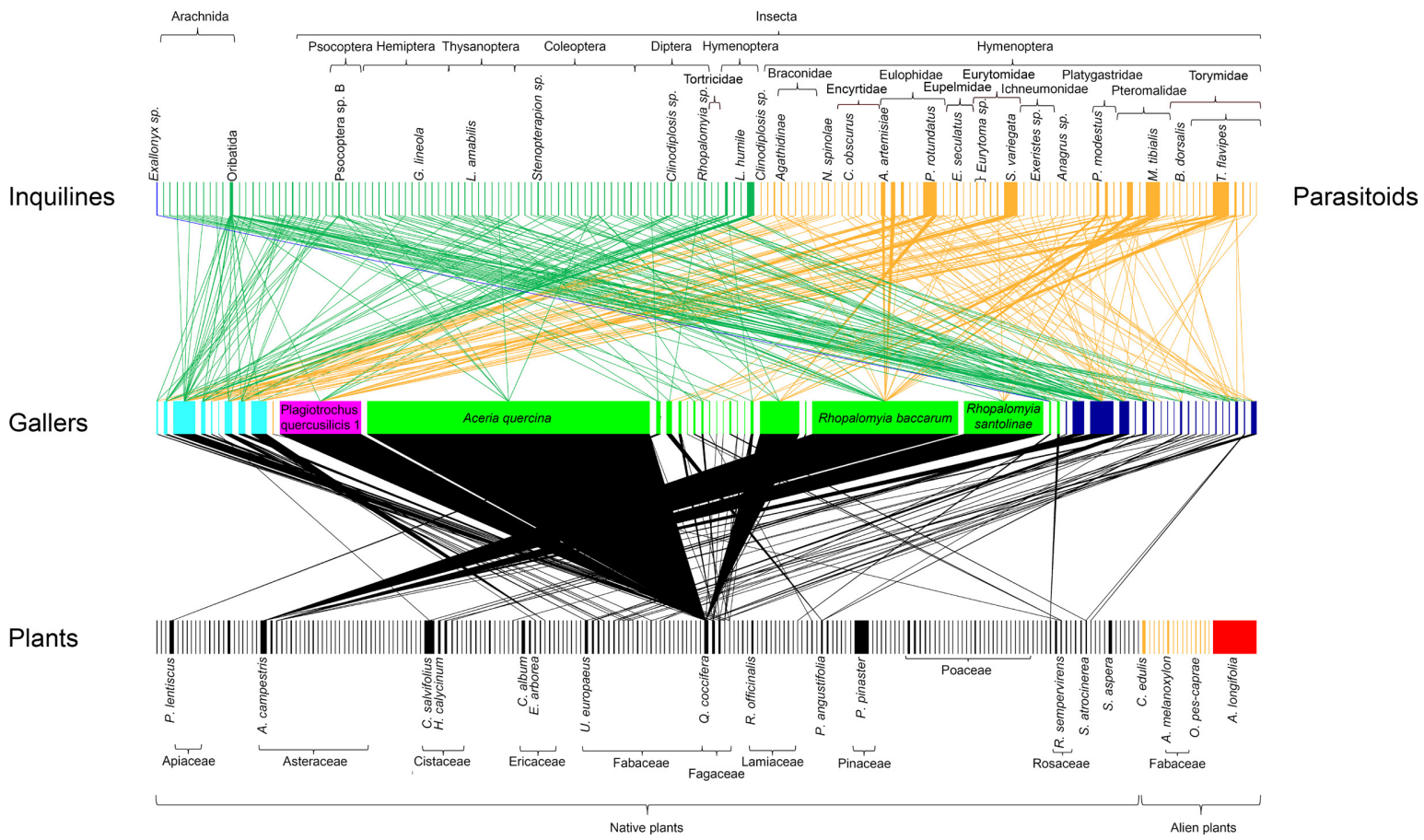

FIG. 1. Visualization of the overall interaction network (all field sites) quantifying the interactions between plants (bottom level), gallers (intermediate level), their parasitoids (top level: green) and inquilines (top level: yellow). Within each trophic level, the width of each species bar is proportional to its relative abundance. Although parasitoids interact with gallers and inquilines interact with the galls (which are formed by plant tissue), these two guilds were represented at the same trophic level because they both require the specific interaction with gallers. Native plant species are represented in black, alien plant species represented in yellow and the invasive Acacia longifolia is represented in red (bottom). Color of the boxes representing the gallers reflects the plant organ where the galls have been collected, namely: vegetative buds in light blue, flower buds in purple, leaves in green, and stems in dark blue. [Color figure can be viewed at wileyonlinelibrary.com] 
plant) and most gallers colonized only one plant species (level of specialization $=1.07$ plant/galler species; Fig. 1). The exception to this high specialization were oak trees (Quercus spp.), which harboured on average 6.8 galler species $(\min =4 ; \max =10)$. Quercus coccifera was by far the most important host plant for gallers, being infected by 10 species, including the most abundant galler Aceria quercina.

Arthropods emerged from $75 \%$ of all collected galls, of which $66 \%$ were gallers, $28 \%$ were parasitoids, and $6 \%$ were inquilines. All of the above allowed the quantification of 10,257 unique interactions, represented in Fig. 1. Remarkably, despite the large sampling effort, no galls were ever found on A. longifolia or on any other alien plant species (Fig. 1).

\section{Impact of invasion on biodiversity}

Despite considerable variability in the data, our results clearly show a significant trend for the reduction of biodiversity as a result of $A$. longifolia invasion (Fig. 2). The increase in the proportion of A. longifolia cover was significantly associated with a simplification of the invaded communities by reducing the richness and abundance of plants (Fig. 2a, e), the biomass of galls (Fig. 2i), and the richness, abundance and biomass of gallers (Fig. 2b, f, j), parasitoids (Fig. 2c, g, k), and inquilines (Fig. 2h, 1). Moreover, we detected a significant decline in the richness of pairwise interactions established between species of the four trophic levels, i.e., a reduction in the number of unique interactions established between plants and gallers (Fig. 3a), between gallers and their parasitoids (Fig. 3b), and between galls and their inquilines (Fig. 3c).

\section{Impact of invasion on community structure}

In all sites, a rich native plant community was replaced by much less diverse vegetation dominated by $A$. longifolia. Although the structure of the networks varied considerably within and across sites, we detected very few consistent changes in network structure descriptors as a result of A. longifolia invasion (Fig. 4). Noticeably, interaction evenness showed a trend to increase at higher levels of invasion (Table 1). No consistent variation was observed between any other topological descriptors of network structure: in Quiaios and in São Pedro de Moel invasion translated into a steady simplification of the whole network, while in Lagoa da Vela and Bandeira an increase in the number of interactions at intermediate levels of invasion was observed, followed by a network simplification on highly invaded sites (Fig. 4).

\section{Potential for apparent competition among galler species}

On average, the potential for pairwise apparent competition among all galler species was extremely low $(\mathrm{PAC}=0.016, \mathrm{SD}=0.078)$, however, there was a high
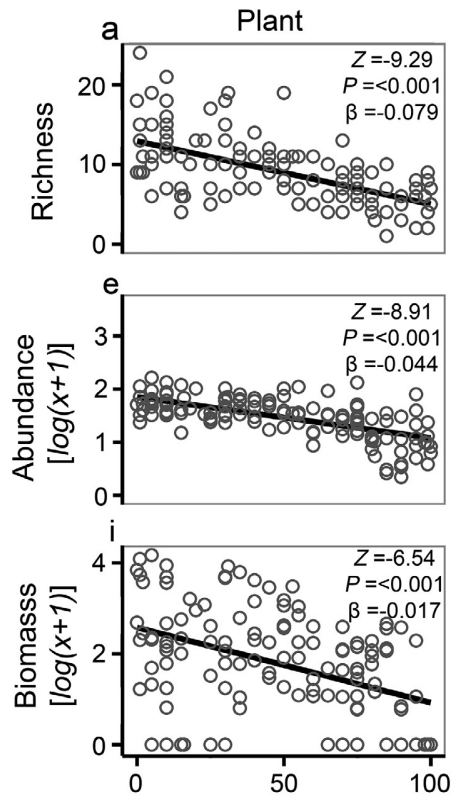

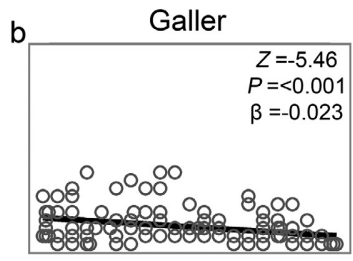

f
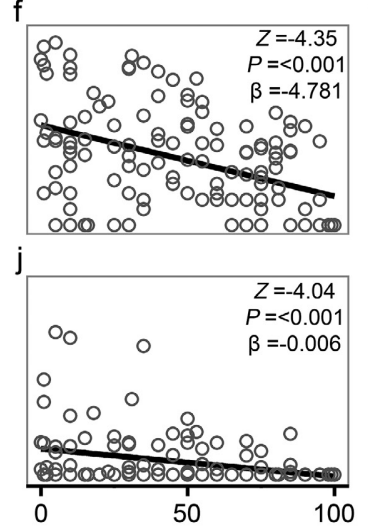

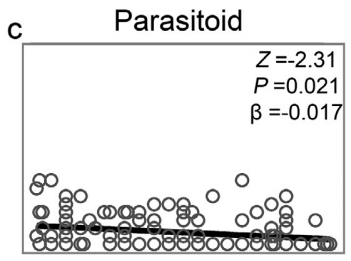

g
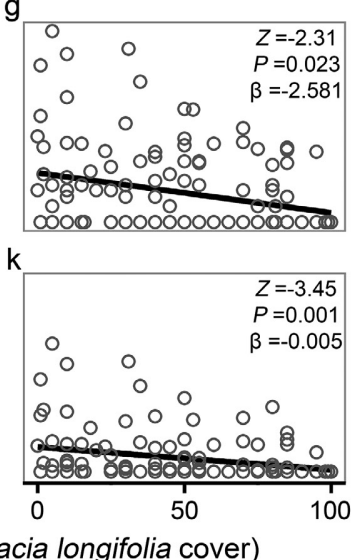

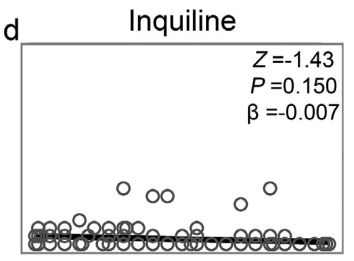

$\mathrm{h}$
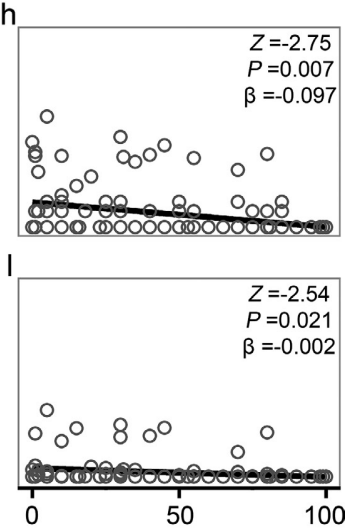

FIG. 2. Effect of Acacia longifolia invasion on richness and abundance of plants, gallers, parasitoids and inquilines, and biomass of galler insects and their associated insect communities detected along transects, in the four sites regularly-sampled. The biomass of plants refers exclusively to the biomass allocated to the production of gall tissues (an estimate of the resource available to inquilines), and not to the biomass of the whole plant. The significance of these relationships was estimated using generalized linear mixed models (see Materials and methods). The $P$-value, the $z$-value of each GLMM, and the slope of the regression model $(\beta)$ is indicated. 


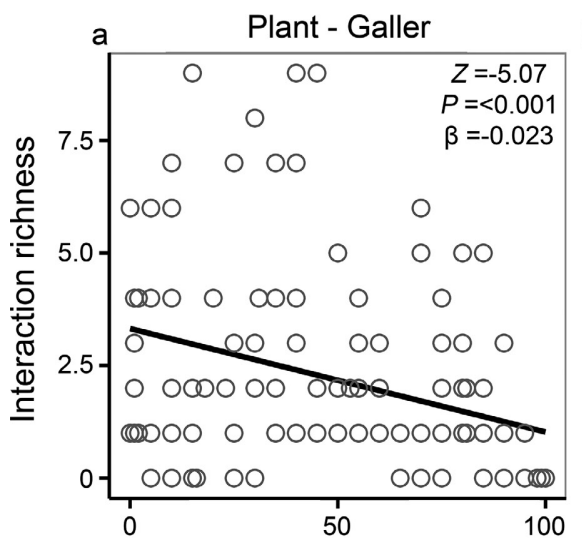

Galler - Parasitoid

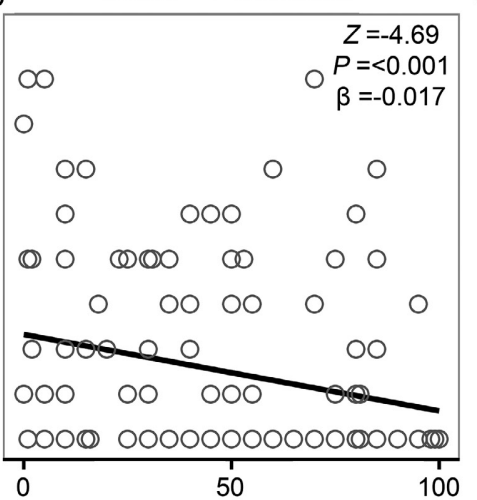

c Gall - Inquiline

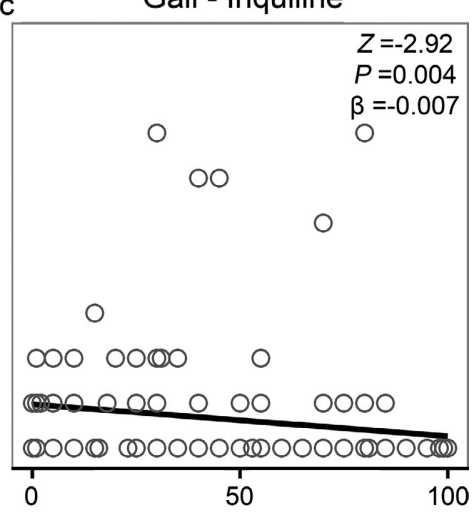

Invasion (\% Acacia longifolia cover)

FIG. 3. Effect of Acacia longifolia invasion on the richness of interactions detected between each trophic levels, in the four regularly sampled sites. The significance of these relationships was estimated using generalized linear mixed models (see Materials and methods). The $P$-value, the $z$-value of each GLMM, and the slope of the regression model ( $\beta$ ) is shown.
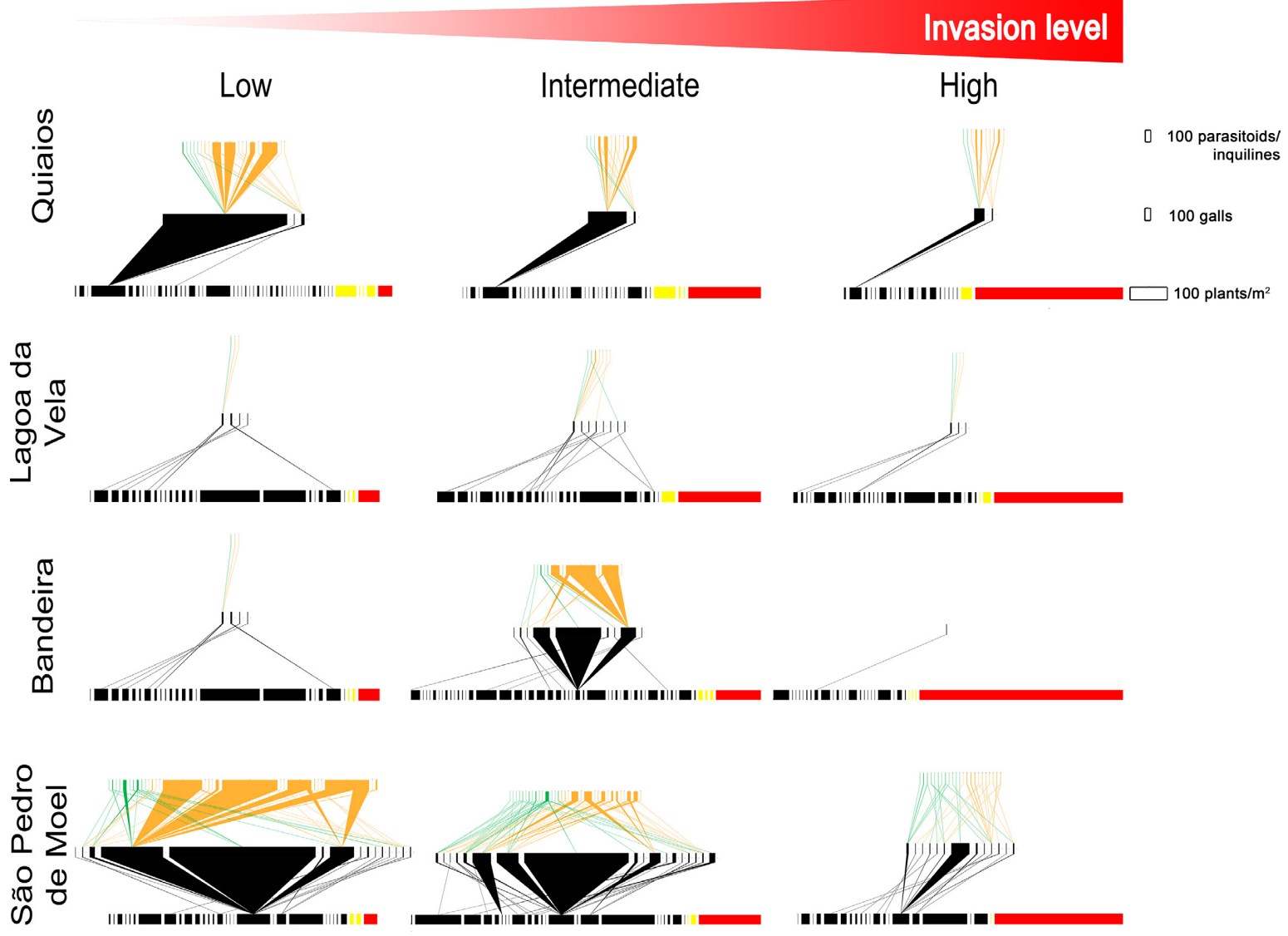

FIG. 4. Quantitative interaction networks representing the interactions between plants (bottom), gallers (intermediate level), parasitoids (top green) and inquilines (top orange) along a gradient of Acacia longifolia invasion in four regularly-sampled sites along the coast of Portugal. Native plants are represented in black, alien plants in yellow and A. longifolia in red. [Color figure can be viewed at wileyonlinelibrary.com] 
TABLE 1. Estimated effect of the level of Acacia longifolia invasion on the structure of the gall communities along the four regularlysampled sites along the coast of Portugal, namely: QU, Quiaos; LV, Lagoa da Vela; BA, Bandeira and SPM, São Pedro de Moel.

\begin{tabular}{|c|c|c|c|c|c|c|c|c|c|c|c|c|}
\hline \multirow{2}{*}{$\begin{array}{l}\text { Interaction } \\
\text { type }\end{array}$} & \multirow[b]{2}{*}{ Descriptor } & \multicolumn{3}{|c|}{ Invasion level } & \multirow{2}{*}{$\begin{array}{c}\text { Test } \\
\text { statistic } \\
\chi_{(\mathrm{df}=2)}^{2}\end{array}$} & \multirow[b]{2}{*}{$P$} & \multicolumn{4}{|c|}{ Site } & \multirow{2}{*}{$\begin{array}{c}\text { Test } \\
\text { statistic } \\
\chi_{(\mathrm{df}=3)}^{2}\end{array}$} & \multirow[b]{2}{*}{$P$} \\
\hline & & Low & Intermediate & High & & & QU & LV & $\mathrm{BA}$ & SPM & & \\
\hline \multirow{4}{*}{$\begin{array}{l}\text { Plant- } \\
\text { Galler }\end{array}$} & Connectance & 0.29 & 0.37 & 0.65 & 0.274 & 0.104 & 0.83 & 0.29 & 0.44 & 0.18 & 0.400 & 0.085 \\
\hline & $\begin{array}{c}\text { Interaction } \\
\text { evenness }\end{array}$ & 0.23 & 0.32 & 0.33 & 0.020 & 0.194 & $0.21^{\mathrm{a}}$ & $0.43^{\mathrm{b}}$ & $0.22^{\mathrm{a}}$ & $0.27^{\mathrm{a}}$ & 0.088 & 0.002 \\
\hline & $\begin{array}{l}\text { Nestedness } \\
\text { (WNODF) }\end{array}$ & 0.76 & 1.65 & 0 & 3.393 & 0.687 & 0 & 1.36 & 1.56 & 0.3 & 2.584 & 0.903 \\
\hline & $\begin{array}{l}\text { Specialization } \\
(\mathrm{H} 2)\end{array}$ & 1 & 0.992 & 1 & $\begin{array}{c}7.15 \times \\
10^{-5}\end{array}$ & 0.570 & 1 & 0.999 & 0.997 & 0.99 & $\begin{array}{l}1.107 \times \\
10^{-4}\end{array}$ & 0.629 \\
\hline \multirow{4}{*}{$\begin{array}{l}\text { Galler- } \\
\text { Parasitoid }\end{array}$} & Connectance & 0.56 & 0.41 & 0.57 & 0.013 & 0.877 & $0.59^{\mathrm{a}}$ & $0.83^{\mathrm{a}}$ & $0.4^{\mathrm{a}}$ & $0.16^{\mathrm{b}}$ & 1.332 & $<0.001$ \\
\hline & $\begin{array}{c}\text { Interaction } \\
\text { evenness }\end{array}$ & 0.53 & 0.42 & 0.69 & 0.122 & 0.237 & 0.52 & 0.67 & 0.48 & 0.44 & 0.105 & 0.476 \\
\hline & $\begin{array}{l}\text { Nestedness } \\
\text { (WNODF) }\end{array}$ & 15.4 & 14.7 & 2.71 & 235.11 & 0.505 & 19.96 & 0 & 16.26 & 5.98 & 585.48 & 0.333 \\
\hline & $\begin{array}{l}\text { Specialization } \\
(\mathrm{H} 2)\end{array}$ & 0.61 & 0.59 & 0.96 & 0.198 & 0.333 & 0.61 & 1 & 0.54 & 0.73 & 0.246 & 0.435 \\
\hline \multirow{4}{*}{$\begin{array}{l}\text { Gall- } \\
\text { Inquiline }\end{array}$} & Connectance & $0.51^{\mathrm{a}}$ & $0.41^{\mathrm{a}}$ & $0.72^{\mathrm{a}}$ & 0.198 & $<0.001$ & $0.67^{\mathrm{a}}$ & $0.98^{a}$ & $0.26^{\mathrm{b}}$ & $0.18^{\mathrm{b}}$ & 0.824 & $<0.001$ \\
\hline & $\begin{array}{c}\text { Interaction } \\
\text { evenness }\end{array}$ & $0.35^{\mathrm{a}}$ & $0.55^{\mathrm{ab}}$ & $0.81^{\mathrm{b}}$ & 0.328 & $<0.001$ & 0.61 & 0.9 & 0.32 & 0.48 & 0.179 & 0.064 \\
\hline & $\begin{array}{l}\text { Nestedness } \\
\text { (WNODF) }\end{array}$ & 2.9 & 6.7 & 11.2 & 56.44 & 0.591 & 0 & 0 & 0 & 15.6 & 482.40 & 0.029 \\
\hline & $\begin{array}{l}\text { Specialization } \\
\text { (H2) }\end{array}$ & $0.92^{\mathrm{a}}$ & $0.52^{\mathrm{a}}$ & $0.75^{\mathrm{a}}$ & 0.202 & 0.009 & - & $0^{\mathrm{a}}$ & $1^{b}$ & $0.72^{\mathrm{b}}$ & $0.492 \dagger$ & $<0.001$ \\
\hline
\end{tabular}

Notes: Network structure descriptors where calculated independently for the bipartite interactions between each trophic levels. The test statistic presented refer to the significance of each variable tested with GLMs. Different letters between levels represent significant differences identified by the Tuckey post-hoc test.

$\dagger$ Test statistic with 2 degrees of freedom.

variability on the PAC across species pairs $(\mathrm{min}=0$, $\max =0.782 ;$ Appendix S3: Table S1). The galler species with the highest potential to affect the remaining galler community was Watchtliella ericina (Cumulative PAC = 4.106; Table 2, Fig. 5) followed by Plagiotrochus quercusilicis 1 (Cumulative PAC $=2.165$ ).

Although there is very little information available, particularly in its native range, we found records for 26 parasitoids species (from four families) and two species of inquilines (one family) that interact with Trichilogaster acaciaelongifoliae in Australia and South Africa (Appendix S4: Table S1). Using this list, we predicted the PAC of the biocontrol agent to vary from zero, if it interacts only with its currently known parasitoid species (Fig. 5, left panel), to pervasive, if the biocontrol agent interacts with all parasitoids from the families from which at least one parasitoid is known (Fig. 5, right panel).

\section{DiscusSION}

We applied a large-scale, replicated, communitylevel approach to clarify the indirect impact of Acacia longifolia invasion on the communities of plants, gallers, their parasitoids and inquilines. The overall resulting network represents one of the largest terrestrial networks assembled to date with important implications for understanding the indirect impacts of an aggressive invasive plant and for planning and evaluating its biocontrol.

Although more than 30,000 galls were observed during this study, no galls were found on any alien plant, indicating that these alien species did not bring their native gall enemies when they were introduced, despite at least some of them being known to have galls in the native range (e.g., A. longifolia, Neser 1984, or Robinia pseudoacacia, Molnar et al. 2009).

\section{Impact of invasion on biodiversity}

Our results confirm previous works (Marchante et al. 2015) showing that the invasion by $A$. longifolia in Portugal followed the general pattern of many plant invasions: a rich native plant community was simplified as it became gradually replaced by an impoverished vegetation dominated by one alien plant species. Yet, our results add key information at novel, unexplored levels: namely that this significant habitat simplification reduced the diversity of host plants available for gallers (Fig. 2a, e), which resulted in the reduction in the richness, abundance and biomass of gallers (Fig. 2b, f, j), and consequently on overall gall biomass produced (Fig. 2i). This effect cascaded further through the food web, reducing the richness, abundance and biomass of the parasitoids of the gallers (Fig. 2c, g, k) and of the arthropod inquilines living inside the galls (Fig. 2d, h, 1). 
TABLE 2. Estimated cumulative potential for apparent competition (PAC) of each galler species via shared parasitoids with other gallers (data from all field sites).

\begin{tabular}{|c|c|c|}
\hline Galler species & Code & $\begin{array}{l}\text { Cumulative } \\
\text { PAC }\end{array}$ \\
\hline Wachtliella ericina & 31 & 4.106 \\
\hline Plagiotrochus quercusilicis 1 & 21 & 2.165 \\
\hline Rhopalomyia santolinae & 27 & 1.535 \\
\hline Plagiotrochus quercusilicis 2 & 22 & 1.349 \\
\hline Indeterminated Ulex & 18 & 1.222 \\
\hline Phyllodiplosis cocciferae & 20 & 1.157 \\
\hline Contarinia sp. & 9 & 0.647 \\
\hline Andricus feocundatrix & 2 & 0.569 \\
\hline Plagiotrochus quercusilicis 4 & 24 & 0.370 \\
\hline Plagiotrochus quercusilicis 3 & 23 & 0.344 \\
\hline Rhopalomyia baccarum & 26 & 0.310 \\
\hline Cochylimorpha hilarana & 8 & 0.239 \\
\hline Asphondylia ulicis & 5 & 0.157 \\
\hline Andricus fecundator & 1 & 0.100 \\
\hline $\begin{array}{l}\text { Stenopterapion (Cobosiotherium) } \\
\text { scutellare }\end{array}$ & 28 & 0.095 \\
\hline Andricus kollari & 3 & 0.084 \\
\hline Neuroterus quercusbaccarum & 19 & 0.045 \\
\hline Dithryca guttulosa & 12 & 0.035 \\
\hline Cynips sp. & 10 & 0.032 \\
\hline Dryomyia lichtensteinii & 13 & 0.031 \\
\hline Andricus quercustozae & 4 & 0.030 \\
\hline Cistapion cyanescens & 7 & 0.028 \\
\hline Indeterminated Phillyrea & 15 & 0.016 \\
\hline Rabdophaga salicis & 25 & 0.014 \\
\hline Braueriella phillyreae & 6 & 0.011 \\
\hline Indeterminated Santolina & 17 & 0.004 \\
\hline Indeterminated Q.robur & 16 & 0.001 \\
\hline Hexomyza sarothamni & 14 & $9.9 \times 10^{-5}$ \\
\hline Diplolepis sp. & 11 & 0 \\
\hline Trioza alacris & 29 & 0 \\
\hline Trioza kiefferi & 30 & 0 \\
\hline
\end{tabular}

Note: The column "Code" refers to the numbers in Fig. 5.

The impacts of invasive plants in ecological networks have been most frequently evaluated in pollination and seed dispersal networks (Padrón et al. 2009, Heleno et al. 2012b, Albrecht et al. 2014). However, an understanding of the impacts of biological invasions on the diversity of higher trophic-levels, such as of parasitoids and inquilines, is much scarcer (Heleno et al. 2009, Tylianakis and Binzer 2014). Our study makes a strong contribution to current knowledge of the impacts of invasive species on diversity of different trophic levels, namely on host-parasitoid networks, showing for the first time significant declines along four trophic levels as a result of a plant invasion.

The strength of the negative cascade of effects is probably particularly evident due to the high specificity of plant-gall and gall-parasitoid interactions (Shorthouse et al. 2005). The effects of alien plant invasions on more generalist herbivores has not yet been tested. We hypothesise that such effects will not be so accentuated due to greater trophic plasticity; however, the poverty of plant communities on highly invaded patches is so low (Fig. 2, Marchante et al. 2003, 2015) that even generalist herbivores are likely substantially affected by A. longifolia invasion.

\section{Impact of invasion on community structure}

Despite the well documented impacts of A. longifolia on soil composition and microbiology (Marchante et al. 2008a, b), plant communities (Marchante et al. 2003, 2015, Rascher et al. 2011a), water cycling (Rascher et al. 2011b), nutrient cycling (Rascher et al. 2012), and plant regeneration dynamics (Marchante et al. 2011b, Rascher et al. 2011a), its impacts across multiple trophic-levels at the whole-community level has never been evaluated. Here we adopted an ambitious experimental approach to detect changes along 12 spatially replicated biological communities (i.e., 4 sites $\times 3$ invasion levels), each of them comprising the interactions within four trophic levels (Fig. 4). Although the need to improve the replication of community-level studies has been frequently highlighted (Lopezaraiza-Mikel et al. 2007, Dupont et al. 2009, Pocock et al. 2012, Heleno et al. 2014), we are not aware of any other study undertaking such an ambitious experimental design. Our results show that the communities responded differently to the invasion of $A$. longifolia. On two sites there was a steady simplification of the networks during invasion, while on the other two sites we detected an initial increase in network size followed by a network simplification at higher levels of invasion (Fig. 4). Given the high specialization of most plantgaller and some galler-parasitoid interactions, the composition of the plant communities (i.e., host availability) is particularly important in determining the diversity of higher trophic levels (Redfern 2011). Therefore, the high heterogeneity of the vegetation among the four sites resulted in highly idiosyncratic responses across sites (Table 1), thus hindering the detection of consistent patterns of $A$. longifolia invasion on network structure descriptors. The more consistent trend was an increase of interaction evenness with invasion level (Table 1). This might seem counter-intuitive given that most invasions reduce plant evenness due to the dominance of a few species (Heleno et al. 2009, 2013, Gagic et al. 2011). However, because no single gall was detected on any alien plant (most of them invasive species), and the plant species sustaining high levels of gallers (Quercus spp.) were almost absent in highly invaded sites, the opposite pattern was detected. This implies that with the advance of the invasion, all interactions between plants and gallers became evenly rare (Fig. 4).

\section{Prospects for biocontrol planning}

The level of detail of the interactions represented in Fig. 1 offers an unparalleled reference scenario of the gall communities in Portugal before the release of the biocontrol agent targeting $A$. longifolia. This data set suggests 


\section{Biocontrol agent interacts only with known parasitoids}

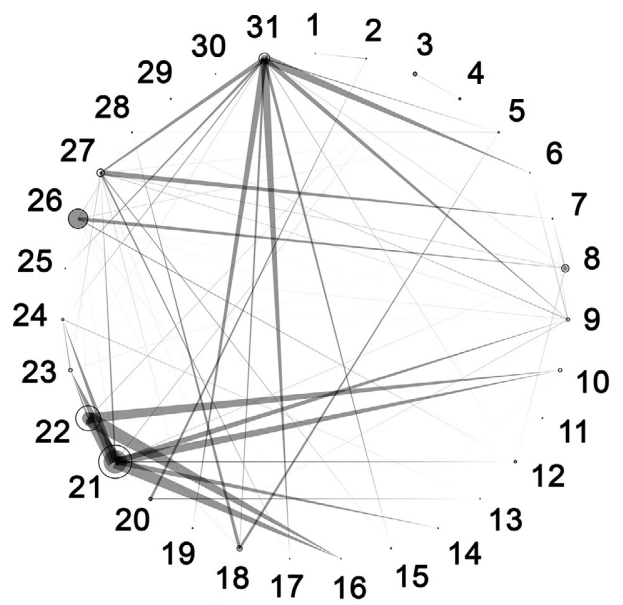

\section{Biocontrol agent interacts with all family members of known parasitoids}

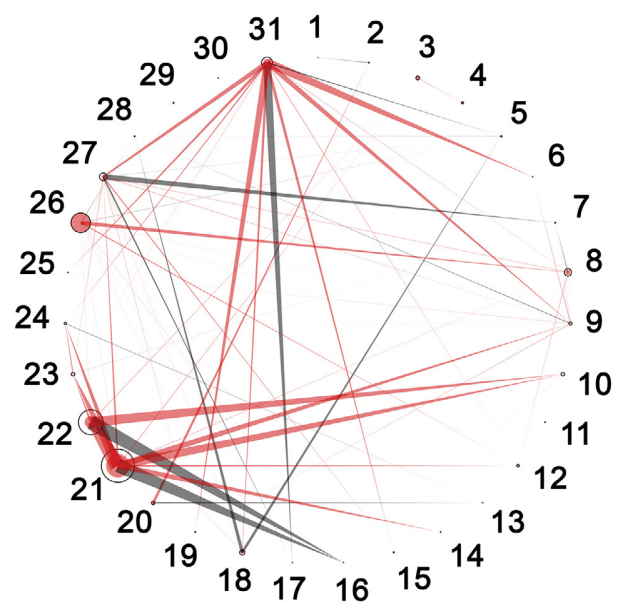

FIG. 5. Projected network of indirect galler-galler interactions, representing in red the potential for apparent competition (PAC) of the biocontrol agent on native gallers via shared parasitoids under two disparate scenarios: (1) a conservative scenario considering that T. acaciaelongifoliae will only interact with parasitoids species currently known to affect it in Australia and South Africa (left) and (2) a liberal scenario considering that Trichilogaster acaciaelongifoliae will interact with all parasitoids from the four families that include their currently known parasitoids (right). The size of each node is proportional to the abundance of the galler species, the filled area of each node represents the potential for auto-infection by parasitoids, the PAC is proportional to the width of each link (triangles). For names of species (numbers), please check Table 2. [Color figure can be viewed at wileyonlinelibrary.com]

that several native gallers may indirectly interact with each other via shared parasitoids (Fig. 5, left panel). At the same time, this network makes a valuable contribution by enabling us to predict potential non-target effects of the biocontrol agent based on the identification of species known to interact with the galls formed by this biocontrol agent elsewhere (as represented in Fig. 5). As could be expected, none of the parasitoid species listed from Australia and South Africa are present in our network, and therefore there is no direct evidence of potential nontarget interactions between local parasitoids and the galls that will be formed by the biocontrol agent once it establishes in Portugal. Nevertheless, two genera of parasitoids in our network (Torymus and Eupelmus) have been previously recorded to interact with the biocontrol agent, with $58.1 \%$ and $22.6 \%$ of our galler species having parasitoids of these genera, respectively. Moreover, our network contains parasitoids from four families that include known parasitoids of Trichilogaster acaciaelongifoliae in Australia and South Africa (Encyrtidae, Eupelmidae, Eurytomidae and Torymidae, with $77.4 \%$ of galler species having parasitoids of these families). Parasitoids from these families are most frequently observed in galls formed in the native plants Artemisia campestris, Cytisus striatus, Stauracanthus spp., Erica cinerea and Quercus coccifera. Although parasitoids tend to be highly specialized (Shorthouse et al. 2005, Noyes 2016), this might not always be the case (Morris et al. 2004, 2005, Carvalheiro et al. 2008, 2010), and it is possible that parasitoids in these families can exploit the biocontrol agent. While this could hinder the establishment of T. acaciaelongifoliae, such is unlikely, as the biocontrol agent successfully established in South Africa despite being exploited by several parasitoid species (Hill and Hulley 1995, Manongi and Hoffmann 1995, Veldtman et al. 2011). On the other hand, if the biocontrol agent becomes established and abundant, some of these parasitoids may increase in abundance, which in turn could spillback (sensu Kelly et al. 2009), by increasing the parasitism rate of native gallers and in the extreme, potentially lead to local extinction of native gallers (Carvalheiro et al. 2008). In all these scenarios, it is critical to carefully weigh the risk of such non-target effects with the risk of doing nothing (Downey and Paterson 2016), that already lead to the local extinction of approximately $30 \%$ of the galler species in highly invaded sites (Fig. 4).

All these scenarios are incredibly hard to predict, largely due to the inexistence of detailed community-level information along all steps of a biocontrol program (Roy and Handley 2012). In this respect, the present work creates a unique opportunity to monitor the outcome of a biocontrol program, laying the bricks for a deeper understanding of community adjustments and towards a more predictable framework for biocontrol worldwide. The evaluation of non-target indirect effects (via apparent competition or multilevel trophic cascades) may make these frameworks more robust and confident.

\section{Concluding Remarks}

This study reveals for the first time that the impacts of Acacia longifolia invasion on native vegetation can cascade through multiple trophic levels along species interaction 
networks, negatively affecting the richness, abundance and biomass of gallers, their parasitoids and inquilines.

The advance of the invasion by $A$. longifolia was shown to change the community structure by increasing interaction evenness as the most important plants for gallers become excluded during the invasion. Nevertheless, despite the severe impacts on all levels of biodiversity, our ambitious experimental design, based on 12 replicated interaction networks, was still insufficient to detect further consistent changes in network topology. These results highlight the uniqueness of ecological communities and the limitations of implementing classic experimental designs (i.e., based on controls, treatments, and replicates) to explore community-level patterns of empirical communities.

The present work provides unparalleled pre-release information against which the success of the biocontrol program can be accurately evaluated in the future. Importantly, our results reveal an alarming simplification of plant and insect communities cascading up four trophic levels following $A$. longifolia invasion and highlight the need to measure potential non-target indirect effects of apparent competition via shared parasitoids with the biocontrol agent.

\section{AcKnowledgments}

We are grateful for the commitment of many dedicated field personnel: P. Castro, S. Carvalho, L. Barrico, N. César de Sá, J. Cerca, J. Costa, A. Martins, L. Silva, J. Costa, D. Alves, E. Almeida, L. Nunes; and the professional taxonomists consulted for arthropods identification: N. Dorchin, L. Friedman, L. Crespo, J.L. Grosso-Silva, M. Alonso-Zarazaga, F. Di Giovanni, G. Broad, A. Polaszek, H. Vardal, A. Franquinho Aguiar, F. Chichorro, C. Prado e Castro, A. M. Ortega, A. R. Gonçalves, and the involved institutions such as Natural History Museum of London and National Research College of Veterinary and Agronomy of Portugal. We thank Catherine O'Connor for revising the English. We are thankful for the insightful comments of Luisa Carvalheiro, Jim Cronin and one anonymous reviewer. RHH was funded by grant IF/00441/2013 of the Portuguese Foundation for Science and Technology (FCT) and by the European Union Marie Curie Action FP72012-CIG-321794. This research and F.A. López-Nuñez was supported by FCT and COMPETE/FEDER, through project "INVADER-B - INVAsive plant species management in Portugal: from early Detection to Remote sensing and Biocontrol of Acacia longifolia". F. A. López-Núñez and R. H. Heleno contributed equally to this work.

\section{REFERENCES}

Albrecht, M., B. Padrón, I. Bartomeus, and A. Traveset. 2014. Consequences of plant invasions on compartmentalization and species' roles in plant-pollinator networks. Proceedings of the Royal Society B 281:20140773.

Almeida-Neto, M., P. Guimarães, P. R. J. Guimarães, R. D. Loyola, and W. Ulrich. 2008. A consistent metric for nestedness analysis in ecological systems: reconciling concept and measurement. Oikos 117:1227-1239.

Barratt, B. I. P., F. G. Howarth, T. M. Withers, J. M. Kean, and G. S. Ridley. 2010. Progress in risk assessment for classical biological control. Biological Control 52:245-254.
Bascompte, J. 2009. Disentangling the web of life. Science 325:416-419.

Bascompte, J. 2010. Structure and dynamics of ecological networks. Science 329:765-766.

Bates, D., M. Mächler, B. Bolker, and S. Walker. 2015. Fitting linear mixed-effects models using $\{1 \mathrm{me} 4\}$. Journal of Statistical Software 67:1-48

Binimelis, R., W. Born, I. Monterroso, and B. RodríguezLabajos. 2007. Socio-economic impact and assessment of biological invasions. Pages 331-347 in M. M. Caldwell, G. Heldmaier, R. B. Jackson, O. L. Lange, H. A. Mooney, E. D. Schulze, and U. Sommer, editors. Biological invasions. Volume 193. First edition. Springer, Berlin, Heidelberg, Germany.

Blüthgen, N., F. Menzel, and N. Blüthgen. 2006. Measuring specialization in species interaction networks. BMC Ecology 6:9.

Carvalheiro, L. G., Y. M. Buckley, and J. Memmott. 2010. Diet breadth influences how the impact of invasive plants is propagated through food webs. Ecology 91:1063-1074.

Carvalheiro, L. G., Y. M. Buckley, R. Ventim, S. V. Fowler, and J. Memmott. 2008. Apparent competition can compromise the safety of highly specific biocontrol agents. Ecology Letters 11:690-700.

Chornesky, E., and J. Randall. 2003. The threat of invasive alien species to biological diversity: setting a future course. Annals of the Missouri Botanical Garden 90:67-76.

Dennill, G. B. 1985. The effect of the gall wasp Trichilogaster acaciaelongifoliae (Hymenoptera:Pteromalidae) on reproductive potential and vegetative growth of the weed Acacia longifolia. Agriculture, Ecosystems \& Environment 14: 53-61.

Dennill, G. B. 1987. Establishment of the gall wasp Trichilogaster acaciaelongifoliae (Pteromalidae) for the biological bontrol of Acacia longifolia in South Africa. Agriculture, Ecosystems \& Environment 19:155-168.

Dirzo, R., H. S. Young, M. Galetti, G. Ceballos, N. J. B. Isaac, and B. Collen. 2014. Defaunation in the Anthropocene. Science 345:401-406.

Dormann, C. F., B. Gruber, and J. Fründ. 2008. Introducing the bipartite package: analysing ecological networks. R News 8:8-11.

Downey, P. O., and I. D. Paterson. 2016. Encompassing the relative non-target risks from agents and their alien plant targets in biological control assessments. BioControl 61:615-630.

Dupont, Y. L., B. Padrón, J. M. Olesen, and T. Petanidou. 2009. Spatio-temporal variation in the structure of pollination networks. Oikos 118:1261-1269.

Fontaine, C., P. R. Guimarães, S. Kéfi, N. Loeuille, J. Memmott, W. H. van der Putten, F. J. F. van Veen, and E. Thébault. 2011. The ecological and evolutionary implications of merging different types of networks. Ecology Letters 14: $1170-1181$.

Fournier, D. A., H. J. Skaug, J. Ancheta, J. Ianelli, A. Magnusson, M. Maunder, A. Nielsen, and J. Silbert. 2012. AD Model Builder: using automatic differentiation for statistical inference of highly parameterized complex nonlinear models. Optimization Methods \& Software 27: 233-249.

Gagic, V., T. Tscharntke, C. F. Dormann, B. Gruber, A. Wilstermann, and C. Thies. 2011. Food web structure and biocontrol in a four-trophic level system across a landscape complexity gradient. Proceedings of the Royal Society B 278:2946-2953.

Gruner, D. S. 2003. Regressions of length and width to predict arthropod biomass in the Hawaiian Islands. Pacific Science 57:325-336. 
Heleno, R. H., R. S. Ceia, J. A. Ramos, and J. Memmott. 2009. Effects of alien plants on insect abundance and biomass: a food-web approach. Conservation Biology 23:410-419.

Heleno, R., M. Devoto, and M. Pocock. 2012a. Connectance of species interaction networks and conservation value: Is it any good to be well connected? Ecological Indicators 14: $7-10$.

Heleno, R. H., J. A. Ramos, and J. Memmott. 2012b. Integration of exotic seeds into an Azorean seed dispersal network. Biological Invasions 15:1143-1154.

Heleno, R. H., J. M. Olesen, M. Nogales, P. Vargas, and A. Traveset. 2013. Seed dispersal networks in the Galápagos and the consequences of alien plant invasions. Proceedings of the Royal Society B 280:20122112.

Heleno, R., et al. 2014. Ecological networks: delving into the architecture of biodiversity. Biology Letters 10:20131000.

Henneman, L., and J. Memmott. 2001. Infiltration of a Hawaiian community by introduced biological control agents. Science 293:1314-1316.

Hill, M. P., and P. E. Hulley. 1995. Host-range extension by native prasitoids to weed biocontrol agents introduced to South Africa. Biological Control 5:297-302.

Hoffmann, J. H., F. A. C. Impson, V. C. Moran, and D. Donnelly. 2002. Biological control of invasive golden wattle trees (Acacia pycnantha) by a gall wasp, Trichilogaster $s p$. (Hymenoptera: Pteromalidae), in South Africa. Biological Control 25:64-73.

Kelly, D. W., R. A. Paterson, C. R. Townsend, R. Poulin, and D. M. Tompkins. 2009. Parasite spillback: A neglected concept in invasion ecology? Ecology 90:2047-2056.

Lopezaraiza-Mikel, M. E., R. B. Hayes, M. R. Whalley, and J. Memmott. 2007. The impact of an alien plant on a native plant-pollinator network: an experimental approach. Ecology Letters 10:539-550.

Manongi, F. S., and J. H. Hoffmann. 1995. The incidence of parasitism in Trichilogaster acaciaelongifoliae (Froggatt) (Hymenoptera: Pteromalidae), a gall-forming biological control agent of Acacia longifolia (Andr.) Willd. (Fabaceae) in South Africa. African Entomology 3:147-151.

Marchante, H., H. Freitas, and J. H. Hoffmann. 2011a. Assessing the suitability and safety of a well-known budgalling wasp, Trichilogaster acaciaelongifoliae, for biological control of Acacia longifolia in Portugal. Biological Control 56:193-201.

Marchante, H., H. Freitas, and J. H. Hoffmann. 2011b. Postclearing recovery of coastal dunes invaded by Acacia longifolia: Is duration of invasion relevant for management success? Journal of Applied Ecology 48:1295-1304.

Marchante, E., A. Kjøller, S. Struwe, and H. Freitas. $2008 a$. Invasive Acacia longifolia induce changes in the microbial catabolic diversity of sand dunes. Soil Biology and Biochemistry 40:2563-2568.

Marchante, E., A. Kjøller, S. Struwe, and H. Freitas. $2008 b$. Short- and long-term impacts of Acacia longifolia invasion on the belowground processes of a Mediterranean coastal dune ecosystem. Applied Soil Ecology 40:210-217.

Marchante, H., E. Marchante, and H. Freitas. 2003. Invasion of the Portuguese dune ecosystems by the exotic species Acacia longifolia (Andrews) Willd.: effects at the community level. Pages 75-85 in L. E. Child, J. H. Brock, G. Brundu, K. Prach, P. Pysek, P. M. Wade, and M. Williamson, editors. Plant Invasions: ecological threats and management solutions. Backhuys Publishers, Leiden, The Netherlands.

Marchante, H., E. Marchante, H. Freitas, and J. H. Hoffmann. 2015. Temporal changes in the impacts on plant communities of an invasive alien tree, Acacia longifolia. Plant Ecology 216:1481-1498.
McCary, M. A., R. Mores, M. A. Farfan, and D. H. Wise. 2016. Invasive plants have different effects on trophic structure of green and brown food webs in terrestrial ecosystems: a metaanalysis. Ecology Letters 19:328-335.

Memmott, J. 2009. Food webs: A ladder for picking strawberries or a practical tool for practical problems? Philosophical Transactions of the Royal Society B 364:1693-1699.

Molnar, B., T. Boddum, G. Szocs, and Y. Hillbur. 2009. Occurrence of two pest gall midges, Obolodiplosis robiniae (Haldeman) and Dasineura gleditchiae (Osten Sacken) (Diptera: Cecidomyiidae) on ornamental trees in Sweden. Entomologisk Tidskrift 130:113-120.

Montero-Castaño, A., and M. Vilà. 2012. Impact of landscape alteration and invasions on pollinators: a meta-analysis. Journal of Ecology 100:884-893.

Morris, R. J., O. T. Lewis, and H. C. J. Godfray. 2004. Experimental evidence for apparent competition in a tropical forest food web. Nature 428:310-313.

Morris, R. J., O. T. Lewis, and H. C. J. Godfray. 2005. Apparent competition and insect community structure: towards a spatial perspective. Annales Zoologici Fennici 42:449-462.

Neser, S. 1984. A most promising bud-galling wasp, Trichilogaster acaciaelongifoliae (Pteromalidae), established against Acacia longifolia in South Africa. Pages 797-803 in E. S. Delfosse, editor. Sixth International Symposium on Biological Control of Weeds. Vancouver, Ottawa, Canada.

Neto, C. S. 1993. A flora e a vegetação das dunas de S.Jacinto. Finisterra 28:101-148.

Noyes, J. S. 2016. Universal Chalcidoidea Database. World Wide Web electronic publication. http://www.nhm.ac.uk/ chalcidoids

Olesen, J. M., Y. L. Dupont, E. O'Gorman, T. C. Ings, K. Layer, C. J. Melián, K. Trøjelsgaard, D. E. Pichler, C. Rasmussen, and G. Woodward. 2010. From broadstone to Zackenberg: space, time and hierarchies in ecological networks. Pages 169 in G. Woodward, editor. Advances in ecological research. Volume 42. Academic Press, Burlington, Vermont, USA.

Osenberg, C., B. Bolker, J. White, C. St. Mary, and J. Shima. 2006. Statistical issues and study design in ecological restorations: lessons learned from marine reserves. Pages 280-302 in D. Falk, M. Palmer, and L. Zedler, editors. Foundations of restoration ecology. Island Press, Washington, D.C., USA.

Padrón, B., A. Traveset, T. Biedenweg, D. Díaz, M. Nogales, and J. M. Olesen. 2009. Impact of alien plant invaders on pollination networks in two archipelagos. PLoS ONE 4:e6275.

Pfisterer, A. B., B. Schmid, B. P. Andrea, and B. Schmid. 2002. Diversity-dependent production can decrease the stability of ecosystem functioning. Nature 416:84-86.

Pickett, S. T. A. 1989. Space-for-time substitution as an alternative to long-term studies. Pages 110-135 in G. E. Likens, editor. Long-term studies in ecology: approaches and alternatives. Springer-Verlag, New York, New York, USA.

Pocock, M. J. O., D. M. Evans, and J. Memmott. 2012. The robustness and restoration of a network of ecological networks. Science 335:973-977.

Pyšek, P., V. Jarošík, P. E. Hulme, J. Pergl, M. Hejda, U. Schaffner, and M. Vilá. 2012. A global assessment of invasive plant impacts on resident species, communities and ecosystems: the interaction of impact measures, invading species' traits and environment. Global Change Biology 18: $1725-1737$.

R Core Team. 2015. R: a language and environment for statistical computing. R Foundation for Statistical Computing, Vienna, Austria. http://www.R-project.org/

Rascher, K. G., A. Große-Stoltenberg, C. Máguas, J. A. A. Meira-Neto, and C. Werner. 2011a. Acacia longifolia invasion impacts vegetation structure and regeneration dynamics 
in open dunes and pine forests. Biological Invasions 13: 1099-1113.

Rascher, K. G., A. Große-Stoltenberg, C. Máguas, and C. Werner. 2011b. Understory invasion by Acacia longifolia alters the water balance and carbon gain of a Mediterranean pine forest. Ecosystems 14:904-919.

Rascher, K. G., C. Hellmann, C. Máguas, and C. Werner. 2012. Community scale $15 \mathrm{~N}$ isoscapes: tracing the spatial impact of an exotic N2-fixing invader. Ecology Letters 15: 484-491.

Redfern, M. 2011. Plant galls. First edition. Harper Collins Publishers, London, UK.

Redfern, M., and P. Shirley. 2011. British plant galls. Second edition. Field Studies Council Publication, Shropshire, UK.

Roy, H. E., and L. J. L. Handley. 2012. Networking: a community approach to invaders and their parasites. Functional Ecology 26:1238-1248.

Russo, R. 2006. Field guide to plant galls of California and other Western states. University of California Press, Berkley, California, USA

Shaw, R., U. Schaffner, and E. Marchante. 2016. The regulation of biological control of weeds in Europe-an evolving landscape. EPPO Bulletin 46:254-258.

Shorthouse, J. D., D. Wool, and A. Raman. 2005. Gall-inducing insects - nature's most sophisticated herbivores. Basic and Applied Ecology 6:407-411.

Simberloff, D., and B. Von Holle. 1999. Positive interactions of nonindigenous species: Invasional meltdown? Biological Invasions 1:21-32.

Tack, A. J. M., S. Gripenberg, and T. Roslin. 2011. Can we predict indirect interactions from quantitative food webs? - an experimental approach. Journal of Animal Ecology 80: $108-118$

Thomas, M. B., P. Casula, and A. Wilby. 2004. Biological control and indirect effects. Trends in Ecology \& Evolution 19:61; author reply 62-3

Tylianakis, J. M., and A. Binzer. 2014. Effects of global environmental changes on parasitoid-host food webs and biological control. Biological Control 75:77-86.

van Veen, J. F. F., J. Memmott, and C. H. J. Godfray. 2006. Indirect effects, apparent competition and biological control. Pages 145-169 in J. Brodeur and G. Boivin, editors. Trophic and guild in biological interactions control. Springer Netherlands, Dordrecht, The Netherlands.

Veldtman, R., T. F. Lado, A. Botes, Ş. Procheş, A. E. Timm, H. Geertsema, and S. L. Chown. 2011. Creating novel food webs on introduced Australian acacias: indirect effects of galling biological control agents. Diversity and Distributions 17:958-967.

Warren, P. H. 1994. Making connections in food webs. Trends in Ecology \& Evolution 9:136-141.

Werner, C., U. Zumkier, W. Beyschlag, and C. Máguas. 2010. High competitiveness of a resource demanding invasive acacia under low resource supply. Plant Ecology 206: 83-96.

White, E. M., J. C. Wilson, and A. R. Clarke. 2006. Biotic indirect effects: a neglected concept in invasion biology. Diversity and Distributions 12:443-455.

Willis, A. J., and J. Memmott. 2005. The potential for indirect effects between a weed, one of its biocontrol agents and native herbivores: a food web approach. Biological Control 35: 299-306.

\section{SUPPORTING INFORMATION}

Additional supporting information may be found in the online version of this article at http://onlinelibrary.wiley.com/ doi/10.1002/ecy.1701/suppinfo 